OPEN ACCESS

Edited by:

Mónica Pradillo,

Complutense University of Madrid,

Spain

Reviewed by:

Eric Jenczewski,

INRA Centre Versailles-Grignon,

France

Pierre Sourdille,

INRA Centre Auvergne Rhône Alpes,

France

*Correspondence:

Pilar Prieto

pilar.prieto@ias.csic.es

Specialty section:

This article was submitted to

Plant Cell Biology,

a section of the journal

Frontiers in Plant Science

Received: 13 February 2018 Accepted: 13 April 2018

Published: 01 May 2018

Citation:

Calderón MC, Rey M-D, Martín A and Prieto P (2018) Homoeologous Chromosomes From Two Hordeum

Species Can Recognize and Associate During Meiosis in Wheat in the Presence of the Ph1 Locus.

Front. Plant Sci. 9:585. doi: 10.3389/fpls.2018.00585

\section{Homoeologous Chromosomes From Two Hordeum Species Can Recognize and Associate During Meiosis in Wheat in the Presence of the Ph1 Locus}

\author{
María C. Calderón ${ }^{1}$, María-Dolores Rey ${ }^{2}$, Antonio Martín ${ }^{1}$ and Pilar Prieto ${ }^{1 *}$ \\ 1 Plant Breeding Department, Institute for Sustainable Agriculture, Agencia Estatal Consejo Superior de Investigaciones \\ Cientificas (CSIC), Córdoba, Spain, ${ }^{2}$ John Innes Centre, Norwich Research Park, Norwich, United Kingdom
}

Understanding the system of a basic eukaryotic cellular mechanism like meiosis is of fundamental importance in plant biology. Moreover, it is also of great strategic interest in plant breeding since unzipping the mechanism of chromosome specificity/pairing during meiosis will allow its manipulation to introduce genetic variability from related species into a crop. The success of meiosis in a polyploid like wheat strongly depends on regular pairing of homologous (identical) chromosomes and recombination, processes mainly controlled by the Ph1 locus. This means that pairing and recombination of related chromosomes rarely occur in the presence of this locus, making difficult wheat breeding trough the incorporation of genetic variability from related species. In this work, we show that wild and cultivated barley chromosomes associate in the wheat background even in the presence of the Ph1 locus. We have developed double monosomic wheat lines carrying two chromosomes from two barley species for the same and different homoeology chromosome group, respectively. Genetic in situ hybridization revealed that homoeologous Hordeum chromosomes recognize each other and pair during early meiosis in wheat. However, crossing over does not occur at any time and they remained always as univalents during meiosis metaphase I. Our results suggest that the Ph1 locus does not prevent chromosome recognition and pairing but crossing over between homoeologous. The role of subtelomeres in chromosome recognition is also discussed.

Keywords: wheat, barley, homoeologous pairing, introgressions, meiosis, chromosome recognition

\section{INTRODUCTION}

More than two-thirds of global cropland features annual grain crops, which represent roughly $70 \%$ of humanity's food energy needs and typically grown in monoculture. Annual grain production, at its current scale, is fundamentally unsustainable. Thus, the growing human population demands greater crops, more productive and better adapted to specific agro-climatic conditions (Godfray et al., 2010). Plant breeders are playing a major role in worldwide efforts to understand gene functions and interactions with the aim of increasing quality and productivity of major crops. Wide-crossing in plant breeding is an important tool and sometimes the results are the starting point for new crops (Omara, 1953). For example, wide-crossing has been carried out in the Triticeae 
tribe, which includes wheat, to develop new plant species such as $\times$ Triticosecale, obtained after crossing wheat and rye, or $\times$ Tritordeum, an amphyploid between the wild barley Hordeum chilense Roem. et Schult. and wheat (Omara, 1953; Martín and Sanchez-Monge Laguna, 1982). Breeders have also used related species as genetic donors for widening the genetic basis of wheat to get for example wheat cultivars better adapted to specific agro-climatic conditions, improving the quality or carrying resistance to diseases (Lukaszewski, 2000; Liu et al., 2005; Calderón et al., 2012; Rey et al., 2015a). In fact, there are many wild species carrying interesting traits that would be useful to be exploited in wheat breeding programmes, but unfortunately, hybridization between wheat and a wild related species produces only a low level of chromosome pairing and recombination. So understanding wheat genetics and genome organization is essential for plant breeding purposes.

Bread wheat is an hexaploid, which possesses three sets of related chromosomes because of doubling of chromosomes following sexual hybridization between closely related species. However, chromosomes associate regularly in pairs in wheat during meiosis, the cellular process to produce gametes in sexually reproducing organisms. Thus, at meiosis each chromosome only recognize and associate with its homologous and not with the related (homoeologous) chromosomes, which have a similar gene content and order but differ in repetitive DNA sequences. Several pairing homologous $(P h)$ genes control chromosome associations in wheat, although the major effect is due to the Ph1 locus (Sears, 1976). The efficiency of chromosome associations during meiosis have a big influence on the fertility of wheat plants, being crucial for success in breeding, but has a negative effect preventing pairing and recombination between wheat chromosomes and those from related species. Therefore, it seems reasonable to go deeper into the knowledge of the biology of chromosome associations during meiosis in wheat, which will be valuable for wheat breeding.

Chromosome dynamics during meiosis have been extensively studied in a polyploidy such as hexaploid wheat (Moore, 2002; Corredor et al., 2007; Colas et al., 2008; Naranjo and Corredor, 2008). It is now well established that both interactions during recombination at the DNA level and assembly of a meiosisspecific proteinaceous structure known as the synaptonemal complex (SC) play roles in stabilizing associations between homologous chromosomes. However, how homologs became colocalized and how initial recognition is accomplished to establish chromosome associations remains poorly understood. When a chromosome recognizes its homolog (and not another chromosome) in wheat, a localized conformational change in adjacent chromatin is triggered in both partners. This process facilitates recognition and association of homologous versus homoeologous chromosomes and is affected by the Phl locus (Prieto et al., 2005; Greer et al., 2012). Thus, Ph1 stabilizes wheat during meiosis by both, promoting homolog synapsis during early meiosis and preventing homoeologous recombination later in meiosis (Martín et al., 2014, 2017). The effect on synapsis occurs during the telomere bouquet $P h 1$ stage, when promotes more efficient homologous synapsis, thereby reducing the chance of homoeologous synapsis (Martín et al., 2017). The effect on CO formation occurs later in meiosis, when $\mathrm{Ph} 1$ prevents MLH1 sites (Double Holliday Junctions marked to become COs) on synapsed homoeologues from becoming COs. In addition, it has been also described that the level of a ZIP4 paralog included within the $P h 1$ locus alters the number of CO between homoeologous chromosomes (Rey et al., 2017).

Efforts focused on centromeres and telomeres behavior during meiosis have been also made (Martinez-Perez et al., 2000, 2001, 2003; Naranjo et al., 2005). Telomeres, which are highly conserved structures among plants, including wheat (Simpson et al., 1990; Ganal et al., 1991; Schwarzacher and HeslopHarrison, 1991), play an important role on initial chromosome associations at the onset of meiosis. In this stage, the association of telomeres in a bouquet facilitates the search and recognition of homologous chromosomes by bringing chromosomes closer (Corredor and Naranjo, 2007; Koszul et al., 2008; Moore and Shaw, 2009) and its formation is affected by the Ph1 locus (Richards et al., 2012). Subtelomeres, which are the telomere associated sequences (TAS), are highly polymorphic and extraordinarily dynamic sequences (Eichler and Sankoff, 2003). The complex and variable nature of subtelomeres has made difficult to assess the possible functions(s) of these regions so far, but studies on Arabidopsis and Hordeum subtelomeres might suggest a possible role on chromosome specificity between homolog chromosomes at the onset of meiosis (Kotani et al., 1999; Heacock et al., 2004; Calderón et al., 2014). In fact, subtelomeres in Hordeum showed high variability not only from different chromosomes but also among chromosome arms within the same chromosome (Schubert et al., 1998; Prieto et al., 2004b). Thus, the copy number of the subtelomeric HvT01 sequence was variable among chromosomes in both $H$. chilense and $H$. vulgare. Since chromosome associations are initiated at the distal regions of the chromosomes and homologous chromosomes are zipping up from those to the centromeres (Prieto et al., 2004a; Corredor et al., 2007), it seems reasonable to go deeper into the role of the subtelomeric regions on homolog chromosome associations, rather than focusing on features that are common to all chromosomes like telomeres.

The addition of a pair of "alien" chromosomes to the full genome complement of a crop species is commonly used as a first step for accessing genetic variation from the secondary gene pool, but addition lines are also relevant for understanding meiotic pairing behavior and chromosome structure (Friebe et al., 2005; Lukaszewski, 2010). Sets of both cultivated (Hordeum vulgare) and wild ( $H$. chilense) barley addition lines in a hexaploid wheat background were developed (Islam et al., 1978, 1981; Miller et al., 1982) and have potential in plant meiosis studies. Certainly, it allows tracking one specific pair of chromosomes or chromosome segments within the wheat background using genomic in situ hybridization (GISH) and study chromosome rearrangements and associations exclusively in a pair of homologs (Naranjo et al., 2010; Rey et al., 2015b).

In this study, we have developed double monosomic addition lines of wild and cultivated barley in wheat for the same and for different homoeology group to go deeper into the knowledge of chromosome associations during meiosis. These double 
monosomic addition lines enabled to distinguish chromosomes from two different barley species in the wheat background, observe conformational changes during meiosis and analyze whether subtelomeres might play a role on chromosome recognition/pairing at early meiosis in the absence of homologs. Results showed that homoeologous chromosomes can recognize each other to associate correctly in pairs, even in the presence of the $P h 1$ locus, although crossing over does not occur as they remained as univalents during metaphase I.

\section{MATERIALS AND METHODS}

\section{Plant Material}

Crosses between $H$. chilense and $H$. vulgare addition lines in bread wheat (Triticum aestivum cv. Chinese Spring; AABBDD + pair of $\mathrm{H}^{\text {ch }} \mathrm{H}^{\text {ch }}$ and $\mathrm{AABBDD}+$ pair of $\mathrm{H}^{\mathrm{v}} \mathrm{H}^{\mathrm{v}}$, respectively) for the same and for different homoeology group were made to obtain double monosomic wheat lines carrying one $H$. chilense and one $H$. vulgare chromosome for the same and for different homoeology group. $H$. chilense and $H$. vulgare addition lines were kindly provided by Steve Reader, JIC, Norwich, UK. The presence of each Hordeum sp. chromosome in parental and F1 wheat lines used in this work was confirmed by both PCR assays previously described (Liu et al., 1996; Hagras et al., 2005) and in situ hybridization.

Seeds obtained from genetic crosses were germinated on wet filter paper in the dark for 5 days at $4^{\circ} \mathrm{C}$, followed by a period of $24 \mathrm{~h}$ at $25^{\circ} \mathrm{C}$. Plants were then growth in the greenhouse at $26^{\circ} \mathrm{C}$ during the day and $18^{\circ} \mathrm{C}$ during the night (16 h photoperiod).

\section{Fluorescence in Situ Hybridization}

Fluorescence genomic in situ hybridization (GISH) was used to study chromosome associations between $H$. chilense and $H$. vulgare chromosomes in the wheat background as described previously (Prieto et al., 2004b). Root tips were collected from germinating seeds and were pre-treated for $4 \mathrm{~h}$ in a $0.05 \%$ colchicine solution at $25^{\circ} \mathrm{C}$ and fixed in $100 \%$ ethanol-acetic acid, 3:1 (v/v), for at least a week at room temperature. Spikes in meiosis were collected from mature plants and preserved in $100 \%$ ethanol-acetic acid, 3:1 (v/v) until were used to characterize chromosome associations. Chromosome spreads were prepared from both root tips cells and pollen mother cells (PMCs) at meiosis. Root tips and anthers were macerated in a drop of $45 \%$ glacial acetic acid on ethanol-cleaned slides, squashed under a cover slip and dipped in liquid nitrogen in order to fix the plant material on the slide. The cover slip was removed and the slides were air-dried and stored at $4{ }^{\circ} \mathrm{C}$ until used.

Both total genomic $H$. vulgare and $H$. chilense DNA were labeled by nick translation with biotin-11-(Boehringer Mannheim Biochemicals, Germany) and digoxigenin-11-dUTP (Roche Applied Science, Indianapolis, IN, USA), respectively, and used as probes. Both probes were mixed to a final concentration of $5 \mathrm{ng} / \mu \mathrm{l}$ in the hybridization mixture. The hybridization mixture consisted of $50 \%$ formamide, $2 \times$ SCC, 5 ng of biotin-labeled or digoxigenin-labeled probe, $10 \%$ dextran sulfate, $0.14 \mu \mathrm{g}$ of yeast tRNA, $0.1 \mu \mathrm{g}$ of sonicated salmon sperm DNA and $0.005 \mu \mathrm{g}$ of glycogen. Biotin-labeled $H$. vulgare
DNA and digoxigenin-labeled $H$. chilense DNA were detected with a streptavidin- Cy3 conjugate (Sigma, St. Louis, MO, USA) and antidigoxigenin-FITC (Roche Diagnostics, Meylan, France), respectively. Chromosomes were counterstained with DAPI (4', 6-diamidino-2-phenylindole) and mounted in Vectashield (Vector Laboratories, Burlingame, CA, USA).

Chromosome spreads from somatic cells and anthers of the F1 wheat lines were reprobed with the barley subtelomeric tandem repeat HvT01, which was obtained by amplification by the polymerase chain reaction (PCR) from genomic DNA from the barley cv. Betzes using primers made according to the published sequence (Belostotsky and Ananiev, 1990). PCR conditions were previously described by Prieto et al. (2004b). The PCR product corresponding to this barley satellite HvT01 probe was labeled with digoxigenin-11-dUTP, (Roche Applied Science, Indianapolis, IN, USA) by nick translation and detected with antidigoxigenin-FITC (Roche Diagnostics, Meylan, France). Meiosis metaphase samples were also reprobed to label centromeres using the RT sequence included in the barley centromeric BAC7 (Hudakova et al., 2001), amplified by PCR following the same conditions as the amplification of the CCS1 centromeric repeat (Aragón-Alcaide et al., 1996), labeled with biotin-11-(Boehringer Mannheim Biochemicals, Germany) and detected with the streptavidin- Cy3 conjugate (Sigma, St. Louis, MO, USA).

\section{Fluorescence Microscopy and Image Processing}

Hybridization signals were visualized using a Nikon Eclipse $80 \mathrm{i}$ epifluorescence microscope. Images were captured with a Nikon CCD camera using the Nikon 3.0 software (Nikon Instruments Europe BV, Amstelveen, The Netherlands) and processed with Photoshop 11.0.2 software (Adobe Systems Inc., San Jose, California, USA).

\section{Statistical Analysis}

Statistical analyses were performed using STATISTIX 10.0 software (Analytical Software, Tallahassee, FL, USA). Anaphase I combinations were evaluated by an analysis of variance (ANOVA) as a completely randomized design. This analysis included a tangent transformation in the anaphase I combination where only one pole of the meiocytes showed $H$. chilense and $H$. vulgare signals. Tetrad combinations were analyzed by the Kruskal-Wallis test (nonparametric one-way analysis of variance).

\section{RESULTS}

\section{Development of Double Monosomic $H$. vulgare-H. Chilense Addition Lines in Wheat}

Crosses between disomic $H$. chilense and $H$. vulgare addition lines in bread wheat carrying chromosomes $7 \mathrm{H}^{\text {ch }}$ and $7 \mathrm{H}^{\mathrm{v}}$, respectively, were made to obtain double monosomic barley additions in wheat carrying homoeologous $H$. chilense and H. vulgare chromosome 7. Similarly, genetic crosses between 
disomic $H$. chilense and $H$. vulgare addition lines in bread wheat for chromosomes $7 \mathrm{H}^{\text {ch }}$ and $5 \mathrm{H}^{\mathrm{v}}$, respectively, were made to obtain double monosomic wheat lines carrying non-homoeologous chromosomes $7 \mathrm{H}^{\text {ch }}$ and $5 \mathrm{H}^{\mathrm{v}}$. Finally, to corroborate observations on chromosome associations in a different homoeology group, we also developed genetic crosses between disomic $H$. chilense and $H$. vulgare addition lines in bread wheat for chromosomes $5 \mathrm{H}^{\text {ch }}$ and $5 \mathrm{H}^{\mathrm{v}}$, respectively, to obtain double monosomic barley additions in wheat lines carrying homoeologous $H$. chilense and $H$. vulgare chromosomes for group 5. The $F_{1}$ hybrid progeny from each genetic cross was analyzed by GISH to ensure that they retained the expected both $H$. chilense and $H$. vulgare chromosomes (Figure 1). All the plants from all the genetic crosses carried both barley chromosomes. In addition, fluorescence in situ hybridization (FISH) was also performed in these wheat lines using the barley subtelomeric HvT01 repeat as a probe to label polymorphisms between the subtelomeric regions from the $H$. chilense and $H$. vulgare chromosomes added to the wheat background (Figure 1). Chromosome $7 \mathrm{H}^{\mathrm{v}}$ had two strong signals for the barley subtelomeric HvT01 sequence on both chromosome arms meanwhile there was only a weaker signal on the short arm of chromosome $7 \mathrm{H}^{\text {ch }}$. Both $5 \mathrm{H}^{\text {ch }}$ and $5 \mathrm{H}^{\mathrm{v}}$ chromosomes had a signal on the short arm for the HvT01 probe, which was stronger in the case of $5 \mathrm{H}^{\mathrm{v}}$ chromosome, and only a weak signal on the subtelomeric region of the long arm of chromosome $5 \mathrm{H}^{\mathrm{v}}$ was detected, which sometimes cannot be clearly seen and depended on the FISH experiment (Figure 1). No HvT01 subtelomeric signals were detected on the wheat chromosomes. The F1 progeny from each genetic cross was also growth until meiosis with the aim of studying the meiotic behavior of both Hordeum chromosomes by in situ hybridization in PMCs in the wheat background.

\section{Homoeologous Wild and Cultivated Barley Chromosomes Can Fully Associate in Pairs in Wheat in the Presence of the Ph1 Locus}

Chromosome pairing was analyzed during early meiosis by GISH in $F_{1}$ plants carrying one copy of $H$. chilense and one copy of $H$. vulgare homoeologous chromosomes $\left(7 \mathrm{H}^{\mathrm{ch}}\right.$ and $7 \mathrm{H}^{\mathrm{v}}$ ) and it was compared to those carrying non-homoeologous
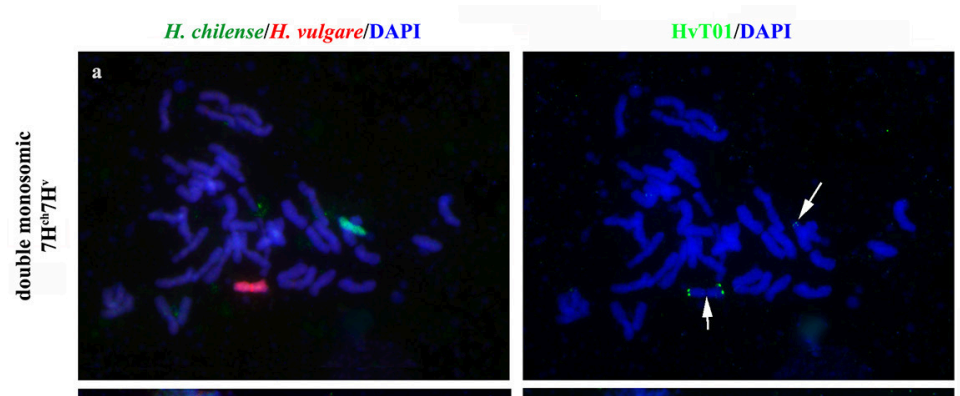

\section{H. chilense/H. vulgarel}

HvT01/DAPI
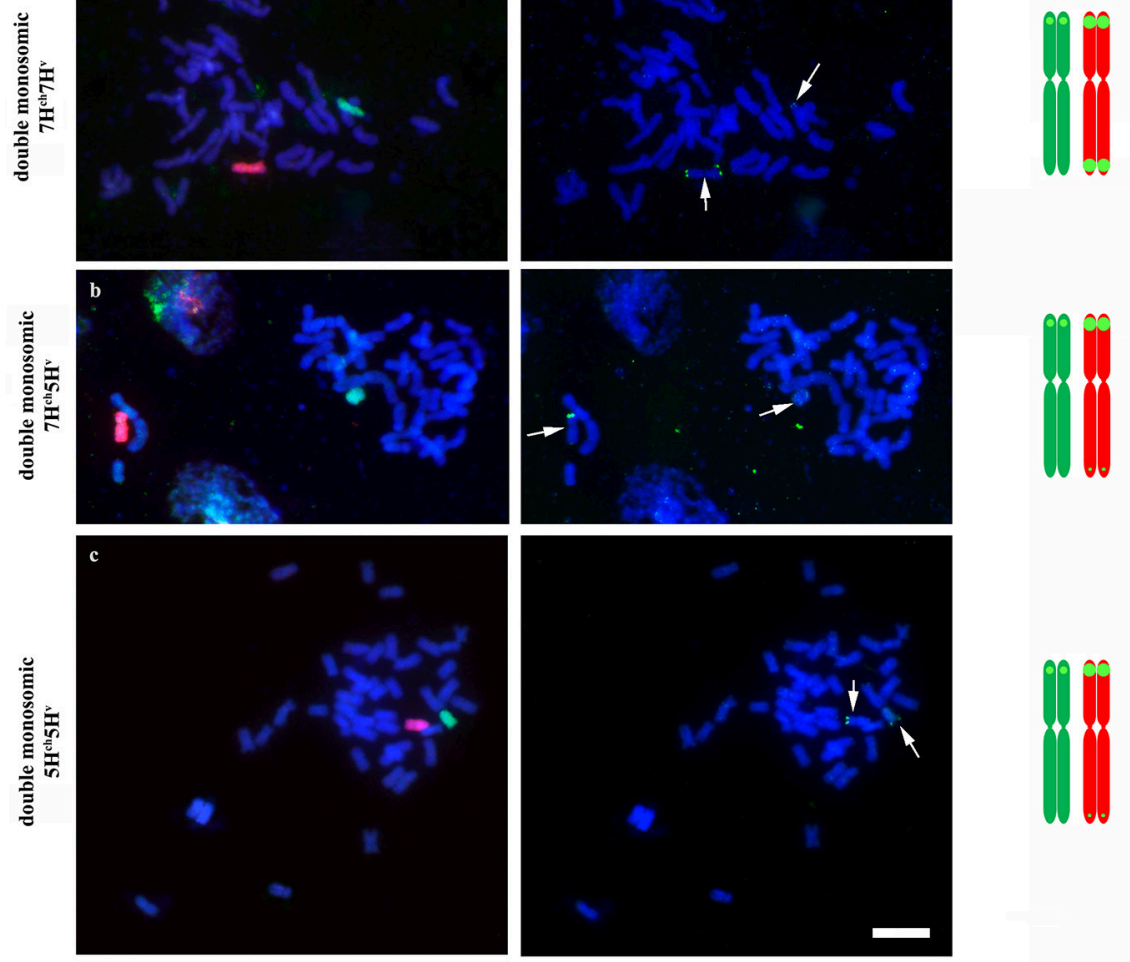

FIGURE 1 | Hordeum chilense and $H$. vulgare double monosomic addition lines in wheat and physical location of the HvT01 subtelomeric repeat on barley chromosomes. Hordeum chilense (green) and H. vulgare (red) chromosomes were detected in GISH experiments in somatic chromosome spreads. In addition, the HvT01 subtelomeric sequence from barley was also detected (green). Total genomic DNA was counterstained with DAPI (blue). (a) Double monosomic $7 \mathrm{H}^{\text {ch }} 7 \mathrm{H}^{\mathrm{V}}$ addition line, including a diagram showing the HvT01subtelomeric signals in all barley chromosome arms, except in $7 \mathrm{H}^{\text {ch }} \mathrm{L}$ arm. (b) Double monosomic $7 \mathrm{H}^{\text {ch }} 5 \mathrm{H}^{\mathrm{v}}$ addition line, including a diagram showing the subtelomeric barley sequence in all barley chromosome arms except in $7 \mathrm{H}^{\text {ch }} \mathrm{L}$ arm. (c) Double monosomic $5 \mathrm{H}^{\mathrm{ch}} 5 \mathrm{H}^{\vee}$ addition line, including a diagram showing the subtelomeric barley sequence in all barley chromosome arms, except in $5 \mathrm{H}^{\mathrm{ch}} \mathrm{L}$ arm. Bar represents $10 \mu \mathrm{m}$. 
$H$. chilense and $H$. vulgare chromosomes $\left(7 \mathrm{H}^{\text {ch }}\right.$ and $5 \mathrm{H}^{\mathrm{v}}$, respectively). Experiments were developed in around a 100 cells of each genomic combination in prophase I of meiosis. Both wild and cultivated barley chromosomes were visualized simultaneously in the wheat background (Figure 2). In both cases, $H$. chilense and $H$. vulgare chromosomes were in proximity in the nucleus in early prophase (Figures 2a,c). As meiosis progressed, GISH experiments showed homoeologous $H$. chilense and $H$. vulgare chromosomes always fully-associated in pairs along the whole chromosome (Figure $\mathbf{2 b}$ ). In contrast, nonhomoeologous Hordeum chromosomes $7 \mathrm{H}^{\mathrm{ch}}$ and $5 \mathrm{H}^{\mathrm{v}}$ were not observed associated at this meiotic stage at any time, remaining always un-associated (Figure 2d).
GISH experiments were also carried out in cells in prophase I of meiosis in $\mathrm{F}_{1}$ plants carrying homoeologous chromosomes from $H$. chilense and $H$. vulgare for another homoeology group (group 5), with the aim of confirming the observations on chromosome associations between homoeologous chromosomes $7 \mathrm{H}^{\text {ch }}$ and $7 \mathrm{H}^{\mathrm{v}}$ in the wheat background. Results showed that homoeologous Hordeum chromosomes $5 \mathrm{H}^{\text {ch }}$ and $5 \mathrm{H}^{\mathrm{v}}$ did also associate in pairs during early meiosis in the wheat background, even in the presence of the Phl locus (Figures 2e,f), suggesting that chromosome pairing between homoeologous chromosomes from two different Hordeum species is not hampered by the Ph1 locus. In addition, results suggested that homoeologous barley chromosomes shared enough similar DNA sequences to
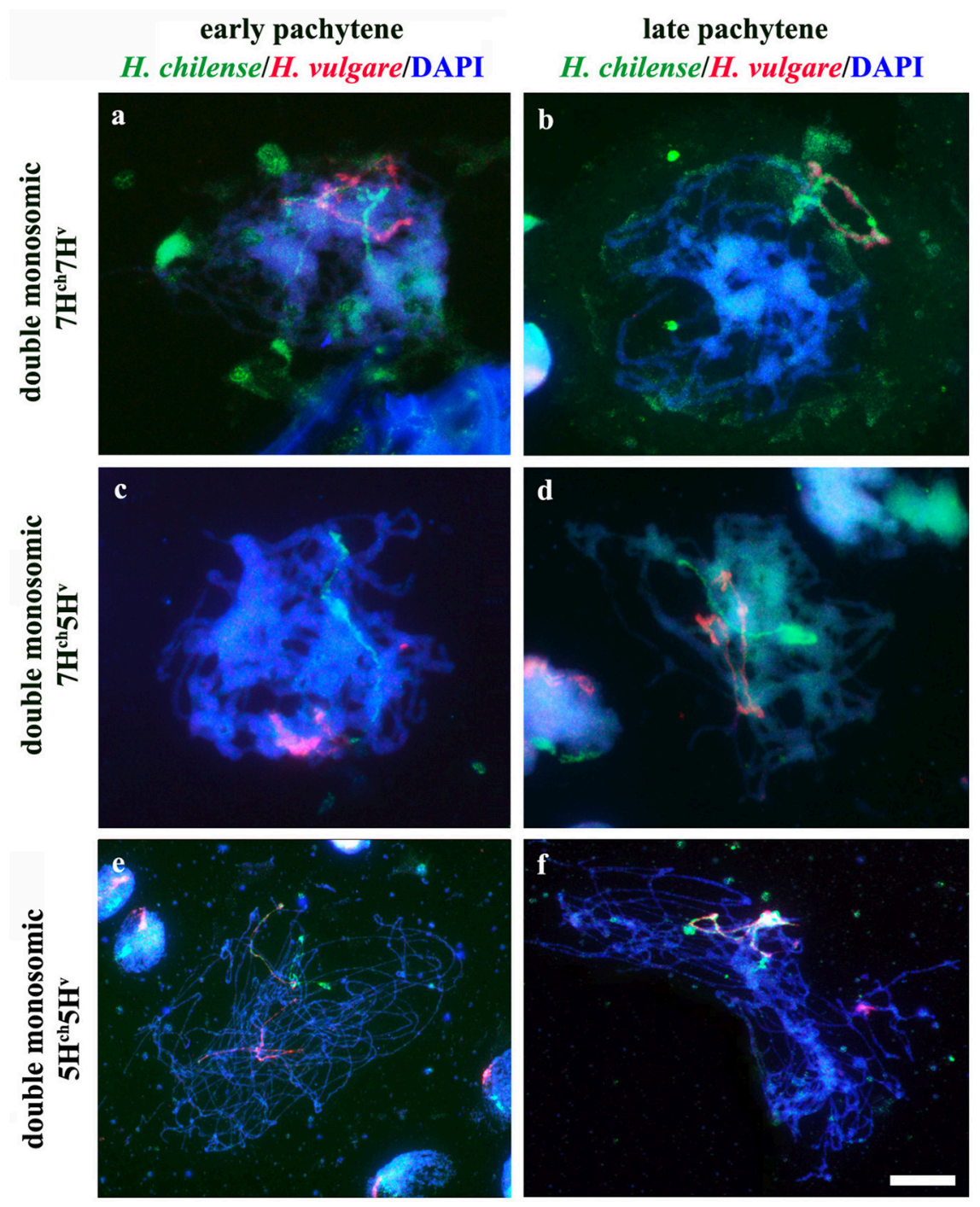

FIGURE 2 | Behavior of homoeologous and non-homoeologous barley chromosomes during early meiosis in wheat. Hordeum chilense chromosomes are visualized in green and $\mathrm{H}$. vulgare chromosomes are visualized in red. (a) Double monosomic $7 \mathrm{H}^{\text {ch }} 7 \mathrm{H}^{\mathrm{v}}$ addition line showing both barley chromosomes un-associated at early pachytene. (b) Homoeologous barley chromosomes are fully associated at late pachytene in the double monosomic $7 \mathrm{H}^{\mathrm{ch}} 7 \mathrm{H}^{\mathrm{V}}$ addition line. (c) Double monosomic $7 \mathrm{H}^{\mathrm{ch}} 5 \mathrm{H}^{\vee}$ addition line showing both barley chromosomes un-associated at early pachytene. (d) Non-homoeologous $7 \mathrm{H}^{\mathrm{ch}}$ and $5 \mathrm{H}^{\vee}$ chromosomes remained un-associated at late pachytene. (e) Double monosomic $5 \mathrm{H}^{\mathrm{ch}} 5 \mathrm{H}^{\mathrm{v}}$ addition line showing homoeologous wild and cultivated barley chromosomes half-paired at early pachytene. (f) Double monosomic $5 \mathrm{H}^{\text {ch }} 5 \mathrm{H}^{v}$ addition line showing both homoeologous Hordeum chromosomes fully associated. Bar represents $10 \mu \mathrm{m}$. 
recognize each other, a conformational chromatin change is observed in both homoeologues and chromosomes are finally associated completely in pairs.

\section{Subtelomeres Might Hamper Chromosome Associations Between Non-homologous Hordeum Chromosomes in the Wheat Background}

We have described that in the absence of homologous chromosomes, wild and cultivated barley homoeologous chromosomes can still recognize each other and associate completely in pairs during early meiosis. In addition, we have observed that, in these cases, initial chromosome recognition occurred by the chromosome ends where none or little copy number of the subtelomeric HvT01 repeat were detected, i.e., the long arm of homoeologous chromosomes $5 \mathrm{H}^{\mathrm{ch}}$ and $5 \mathrm{H}^{\mathrm{v}}$ (Figure 3). Thus, homoeologous Hordeum chromosomes did recognize and associate in pairs by these chromosome ends, which made chromosome recognition less restrictive and allowed homoeologous to recognize and associate in pairs. These observations were similar in the cells detected at the same stage from the double monosomic $7 \mathrm{H}^{\mathrm{ch}} 7 \mathrm{H}^{\mathrm{v}}$ addition line in wheat (data not shown). Moreover, the observations were consistent in all the cells detected at the initiation of pairing (26 and 18 cells from the double monosomic $5 \mathrm{H}^{\mathrm{ch}} 5 \mathrm{H}^{\mathrm{v}}$ and $7 \mathrm{H}^{\mathrm{ch}} 7 \mathrm{H}^{\mathrm{v}}$ addition lines in wheat, respectively). Once homoeologous chromosomes had associated by these chromosome ends, a conformational change was observed along both homoeologous Hordeum chromosomes and pairing progressed along both chromosomes allowing a complete chromosome association between them (Figure 3).

\section{Crossing Over Does Not Occur Between Wild and Cultivated Barley Chromosomes in Wheat Although They Previously Associated in Early Meiosis}

Once we observed full chromosome associations between homoeologous Hordeum chromosomes during early meiosis in the wheat background, we also analyzed chromosome behavior of both wild and cultivated barley chromosomes during metaphase I of meiosis in PMCs from double monosomic H. chilense and $H$. vulgare additions in wheat lines, both for the same and different homoeologous chromosomes. Meiosis metaphase I was also checked in the disomic $H$. chilense and $H$. vulgare addition lines in wheat used as parental lines for the genetic crosses developed in this work, to obtain the double $H$. chilense and $H$. vulgare double monosomic addition lines. Chromosome stability of the parental lines was confirmed as the homologous barley chromosomes carried in the $H$. chilense and $H$. vulgare disomic addition lines were always observed associated in pairs, indicating that crossing over occurred between homologous barley chromosomes (Figure 4). Similarly, wheat chromosomes associated correctly in bivalents at meiosis metaphase I and orientated by centromeres properly in double monosomic $H$. chilense and $H$. vulgare additions in wheat lines, both for the same and different homoeologous chromosomes (Figure 5). In contrast, $H$. chilense and $H$. vulgare chromosomes remained always un-associated in all the cells analyzed for the three different genetic combinations analyzed (Figure 5), despite the fact that homoeologous $H$. chilense and $H$. vulgare chromosomes $\left(7 \mathrm{H}^{\mathrm{ch}} 7 \mathrm{H}^{\mathrm{v}}\right.$ and $5 \mathrm{H}^{\mathrm{ch}} 5 \mathrm{H}^{\mathrm{v}}$, respectively) did completely associate in pairs in early meiosis. These observations suggested that, although wild and cultivated barley homoeologous chromosomes can fully associate during pachytene, crossing over did not occur later between these chromosomes. Consequently, Hordeum homoeologous chromosomes were never observed associated by chiasmata during metaphase I and always remained as univalent (Figure 5), suggesting other requirements for crossing over rather than full previous chromosome associations or similarities in the DNA sequence.

\section{Chromosome Segregation Does Not Depend on Previous Chromosome Associations During Early Meiosis}

Each PMC analyzed at the MI stage was characterized by the presence of two barley univalents in double monosomic $H$. chilense- $H$. vulgare addition lines. Around 300 cells were observed in meiosis anaphase I. GISH analysis showed that both wild and cultivated barley univalents segregated simultaneously

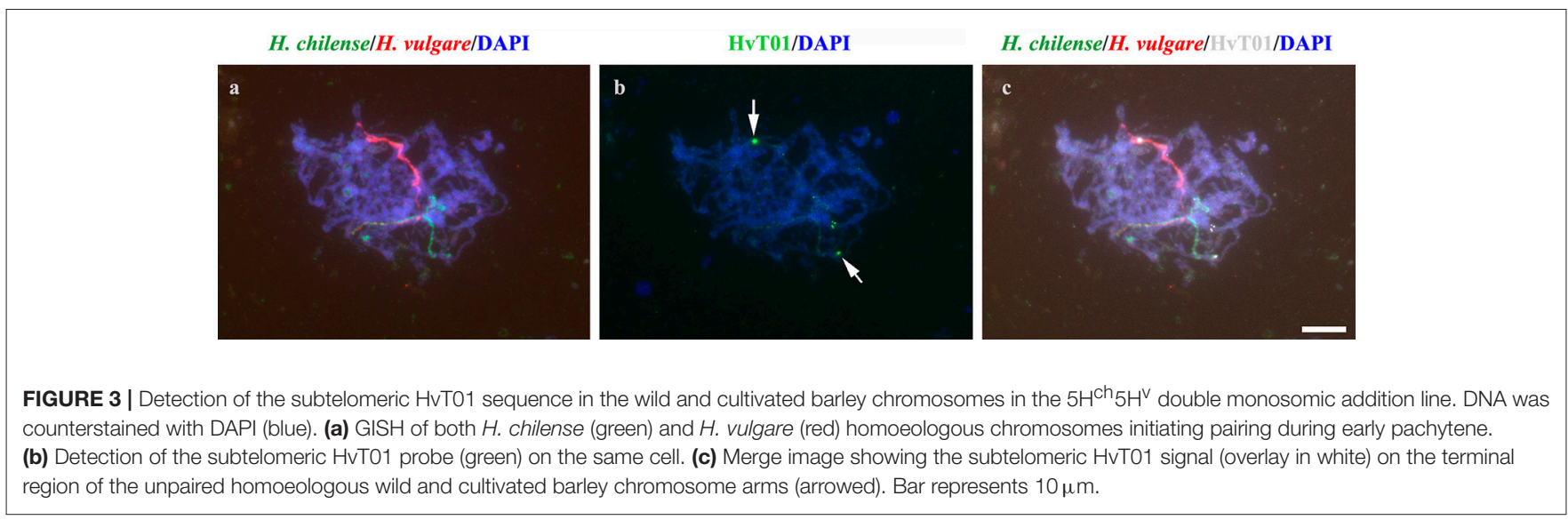



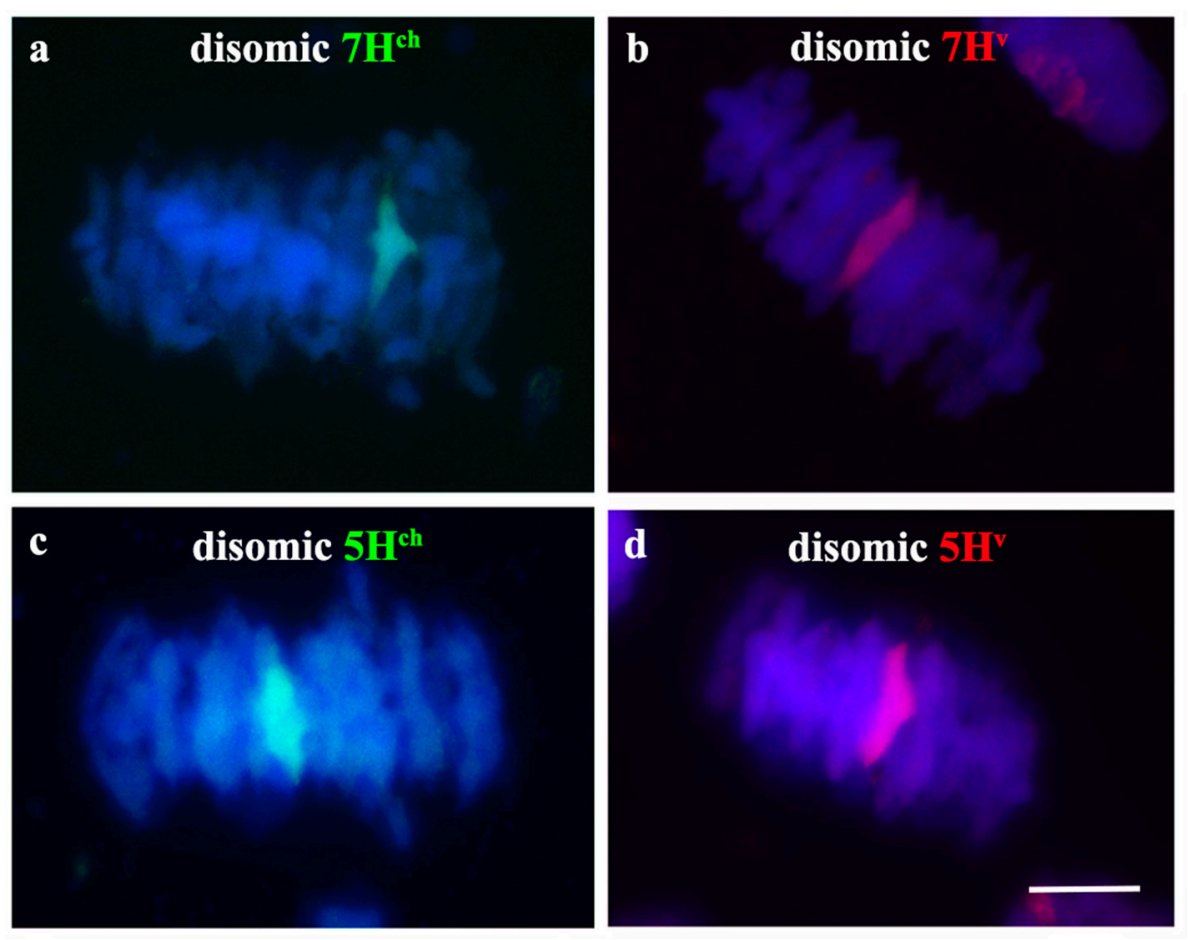

FIGURE 4 | Hordeum chilense and $H$. vulgare chromosome behavior during metaphase I in parental $H$. chilense and $H$. vulgare disosomic addition lines in wheat. Hordeum chilense (green) and $H$. vulgare (red) chromosomes were observed always associated in pairs in all the cells in metaphase I in each $H$. chilense and

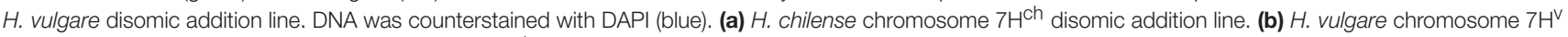
disomic addition line. (c) $\mathrm{H}$. chilense chromosome $5 \mathrm{H}^{\mathrm{ch}}$ disomic addition line. (d) $\mathrm{H}$. vulgare chromosome $5 \mathrm{H}^{\mathrm{v}}$ disomic addition line. Bar represents $10 \mu \mathrm{m}$.

with wheat bivalents at stage anaphase I (Figure 6). All the different possible situations for chromosome segregation of the unpaired $H$. chilense and $H$. vulgare chromosomes were identified (Figures 6a-e, Table 1): (i) both barley chromosome were detected in both nuclei; (ii) only $H$. vulgare chromosome was detected in both nuclei; (iii) only $H$. chilense chromosome was detected in both nuclei; (iv) each barley chromosome was detected in each daughter nucleus; and (v) both barley chromosomes were detected in the same anaphase/telophase pole. These different situations for chromosome segregation of both barley chromosomes were found in all the genetic combinations $\left(7 \mathrm{H}^{\mathrm{ch}} 7 \mathrm{H}^{\mathrm{v}}, 5 \mathrm{H}^{\text {ch }} 5 \mathrm{H}^{\mathrm{v}}\right.$, and $7 \mathrm{H}^{\text {ch }} 5 \mathrm{H}^{\mathrm{v}}$ double monosomic addition lines) in the wheat background, although the ratio between them varied depending on the genetic stock (Table 1). Nevertheless, no significant differences were found for $H$. chilense and $H$. vulgare chromosome segregation between the different genetic combinations (Table 1), despite the fact that the most frequent observation for the segregation of the wild and cultivated barley chromosomes was different in $7 \mathrm{H}^{\mathrm{ch}} 7 \mathrm{H}^{\mathrm{v}}$ addition line compared to $5 \mathrm{H}^{\mathrm{ch}} 5 \mathrm{H}^{\mathrm{v}}$, and $7 \mathrm{H}^{\mathrm{ch}} 5 \mathrm{H}^{\mathrm{v}}$ addition lines (Table 1). Moreover, no significant differences were found on the behavior of the Hordeum chromosomes within the same F1 line. These results suggest that chromosome segregation in double $H$. chilense and $H$. vulgare monosomic addition lines in wheat occurred randomly, regardless the barley chromosomes added to the wheat background and whether or not chromosome associations took place previously in early meiosis.

Chromosomes delay was usually observed in double monosomic $H$. chilense and $H$. vulgare addition lines in late anaphase I/telophase I (Figures 6f,g), and the presence of chromatin across the equator during phragmoplast formation either from $H$. chilense, $H$. vulgare or both species was also observed (Figures $\mathbf{6 h}-\mathbf{j}$ ). Missegregation or chromosome breaks that occurred in anaphase I in the double monosomic $H$. chilense and $H$. vulgare addition lines cannot be distinguished from sister chromatids segregation unless using, among others, the HvT01 subtelomeric probe (Figures 6k, $\mathbf{l}$ ).

Depending on chromosome segregation of both wild and cultivated barley univalents during meiosis $\mathrm{I}$, the number of different genetic combinations in the PMC increased during MII, resulting in a wide range of meiotic phenotypes observed (nineteen different cases; Table 2). The most frequent $H$. chilense and $H$. vulgare chromosome combination observed for each genetic combination during telophase II was different depending on whether $H$. chilense and $H$. vulgare chromosomes were included in the same or in different homoeology group (Figure 7; Table 2), but no significant differences were found. Results suggested that both sister chromatids separation and misdivision did occur randomly independently of the barley chromosome combination. 

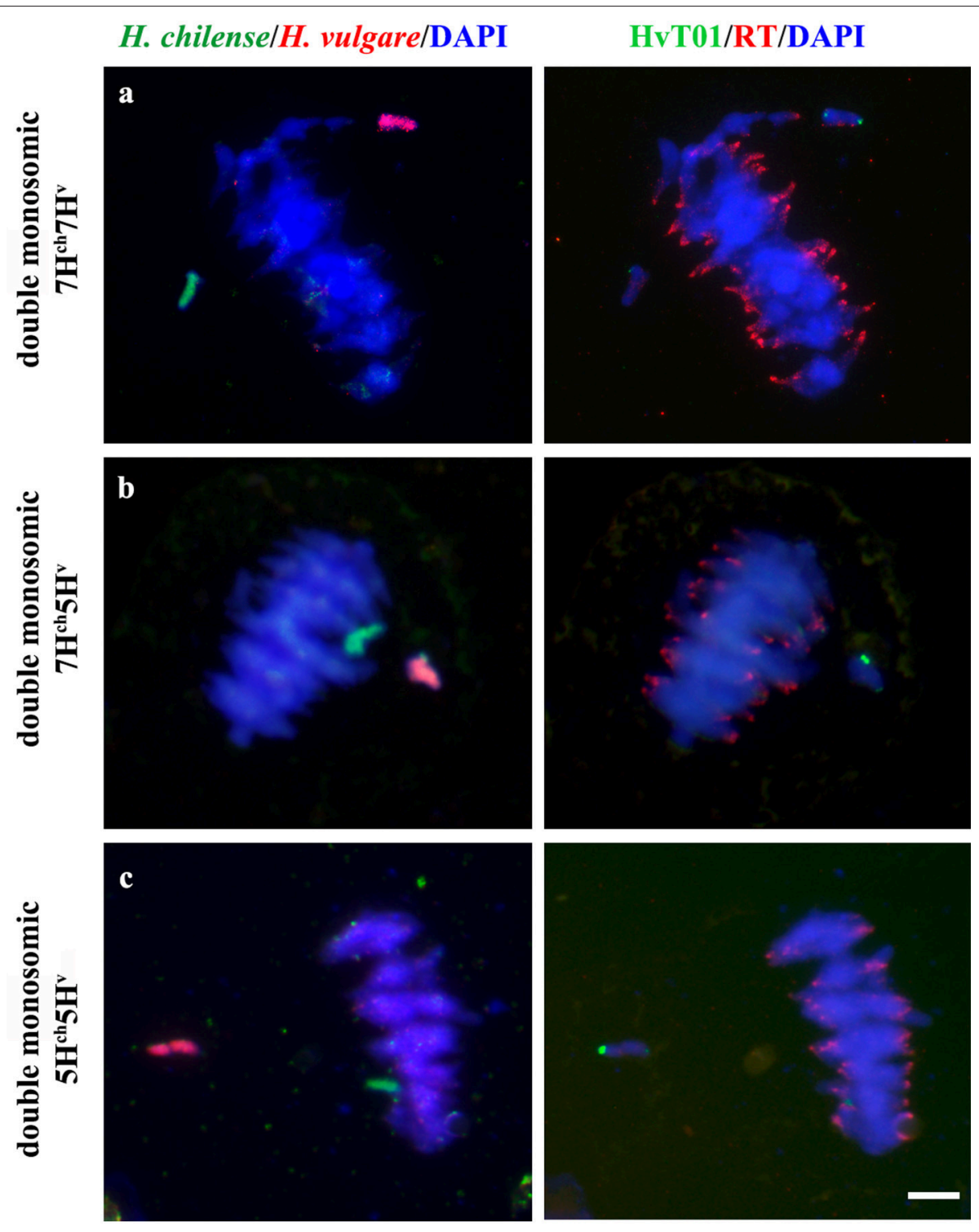

FIGURE 5 | Hordeum chilense and H. vulgare chromosome behavior in double monosomic barley addition lines in wheat during metaphase I. Hordeum chilense (green) and $H$. vulgare (red) chromosomes remained unassociated in all the cases. DNA was counterstained with DAPI (blue). Centromeres (red) were labeled with RT sequence to show the correct orientation of wheat chromosomes during metaphase I. Subtelomeres on barley chromosomes were labeled in green. (a) Double monosomic $7 \mathrm{H}^{\mathrm{ch}} 7 \mathrm{H}^{\vee}$ addition line. (b) Double monosomic $7 \mathrm{H}^{\mathrm{ch}} 5 \mathrm{H}^{\vee}$ addition line. (c) Double monosomic $5 \mathrm{H}^{\text {ch }} 5 \mathrm{H}^{\vee}$ addition line. Bar represents $10 \mu \mathrm{m}$.

\section{DISCUSSION}

Little is known about how chromosomes recognize each other to correctly associate in pairs at early meiosis and recombine. This is a key question for plant breeders to transfer genetic variability from related species into a crop like wheat. The lack of recombination between cultivated wheat and alien chromosomes limits the transfer of novel traits from relatives to wheat because Ph1 suppresses homoeologous recombination between wheat and related species (Riley and Chapman, 1958; Sears, 1976). Different meiosis studies on chromosome pairing have been developed using wheat lines carrying an addition of one pair of homologous chromosomes or chromosome segments from one related species into wheat (Mikhailova et al., 1998; Maestra et al., 2002; Prieto et al., 2004a) or hybrids between wheat and relatives (Molnár-Láng et al., 2014; Rey et al., 2017). In this work, we have developed wheat lines carrying double monosomic chromosome additions for wild and cultivated barley for the same and for different homoeology group, respectively, which allowed us to track simultaneously by GISH a couple of extra homoeologous and non-homoeologous chromosomes from two different Hordeum species during early meiosis. These double monosomic addition lines can contribute to go deeper into the knowledge of how chromosomes recognize and associate in pairs 

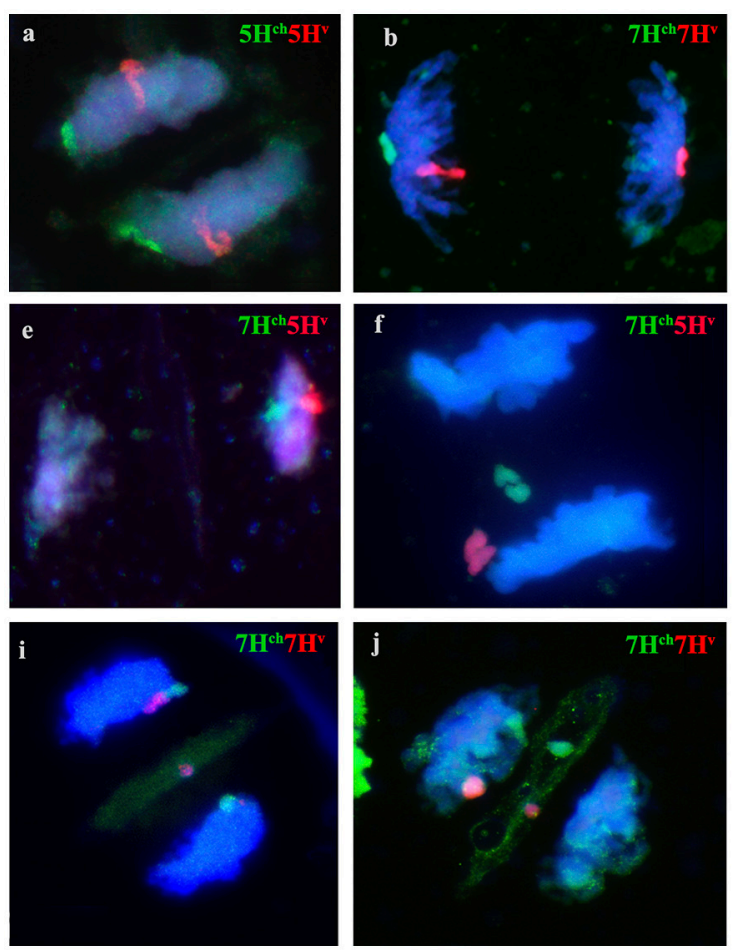
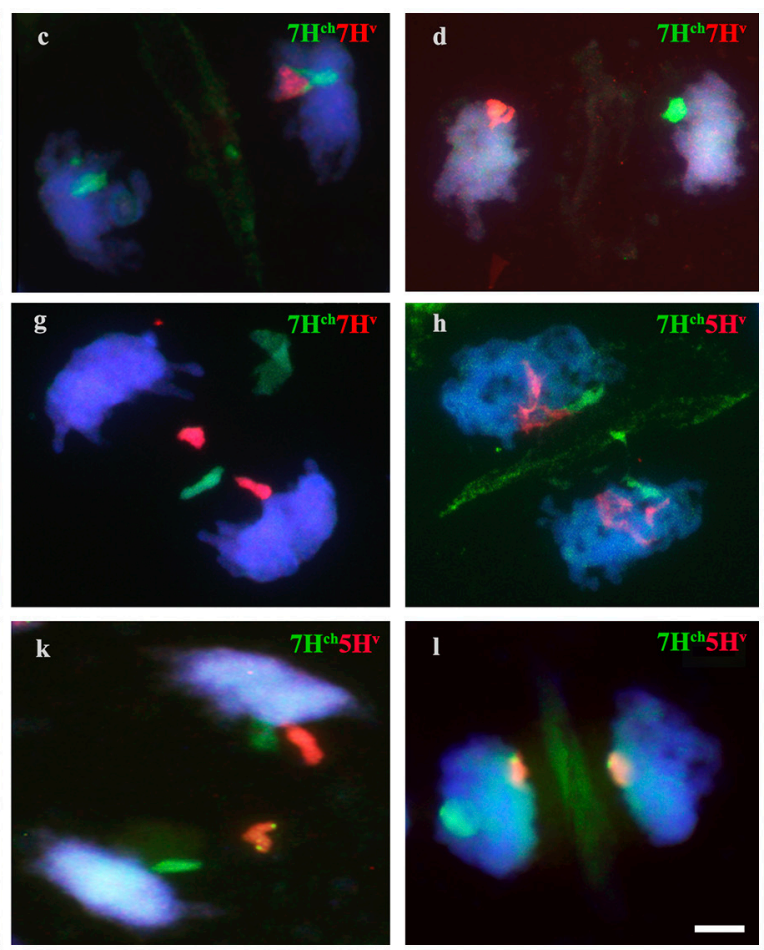

FIGURE 6 | Behavior of Hordeum chilense and H. vulgare chromosomes in double monosomic barley addition lines in wheat during anaphase I of meiosis. Examples of barley chromosome segregation after metaphase I. Hordeum chilense and $H$. vulgare were visualized in green and red, respectively. DNA was counterstained with DAPI (blue). (a) Double monosomic $5 \mathrm{H}^{c h} 5 \mathrm{H}^{\vee}$ addition line, (b) Double monosomic $7 \mathrm{H}^{c h} 7 \mathrm{H}^{\vee}$ addition line, (c) Double monosomic $7 \mathrm{H}^{\text {ch }} 7 \mathrm{H}^{\vee}$ addition line; (d) Double monosomic $7 \mathrm{H}^{\mathrm{ch}} 7 \mathrm{H}^{\mathrm{v}}$ addition line. (e) Double monosomic $7 \mathrm{H}^{\mathrm{ch}} 5 \mathrm{H}^{\mathrm{v}}$ addition line. (f) Both $7 \mathrm{H}^{\mathrm{ch}} 5 \mathrm{H}^{\mathrm{v}}$ barley chromosomes remained delayed. (g) Both $7 \mathrm{H}^{\text {ch }} 7 \mathrm{H}^{\vee}$ barley chromosomes remained delayed and a misdivision of chromosome $7 \mathrm{H}^{\mathrm{v}}$ was also observed. One or both barley micronuclei were positioned in the equatorial region on telophase I in (h) Double monosomic $7 \mathrm{H}^{\mathrm{ch}} 5 \mathrm{H}^{\vee}$ addition line, (i) Double monosomic $7 \mathrm{H}^{\mathrm{ch}} 7 \mathrm{H}^{\vee}$ addition line, and (j) Double monosomic $7 \mathrm{H}^{\mathrm{ch}} 7 \mathrm{H}^{\vee}$ addition line. The subtelomeric HvT01 probe was used in GISH experiments performed in cells in telophase I from the double monosomic $7 \mathrm{H}^{\text {ch }} 5 \mathrm{H}^{\vee}$ addition line to visualize (k) $5 \mathrm{H}^{\vee}$ chromosome misdivision or (I) $5 \mathrm{H}^{\vee}$ chromosome segregation. Bar represents $10 \mu \mathrm{m}$.

in the wheat background in the presence of the $P h 1$ locus. In addition, most of the works carrying alien chromosomes in the wheat background are focused in meiosis metaphase I or later stages (Molnár-Láng et al., 2000; Silkova et al., 2014). The analysis of chromosome pairing focused only in metaphase I can result in an underestimation of homoeologous associations that might occur earlier in meiosis, as chromosomes might remain mostly as univalents due to the lack of homoeologous recombination. Few works analyzed the behavior of an extra pair of chromosomes at early stages of meiosis (Aragón-Alcaide et al., 1997; Prieto et al., 2004a; Valenzuela et al., 2012, 2013; Koo et al., 2016). Homologous barley chromosomes have been previously observed associated during early meiosis and metaphase I in disomic addition lines in wheat (Aragón-Alcaide et al., 1997; Calderón et al., 2014). In this study we have reported by GISH analysis that homoeologous wild and cultivated barley chromosomes can also fully associate in pairs in the wheat background during early meiosis and that such chromosome pairing occurred even in the presence of the Ph1 locus, although homoeologous barley chromosomes did not cross over and were always observed as univalent in metaphase I. The role of the PhI locus was recently narrowed down preventing recombination between related chromosomes in interspecific hybrids (Moore, 2014; Martín et al., 2017). Our results clearly showed that the Ph1 locus does not hamper homoeologous chromosome associations but crossing over. Nevertheless, homoeologous recombination between related Aegilops geniculata and Ae. searsii has been detected in the wheat background in the presence of the Ph1 locus due to the presence of chromosome $5 \mathrm{Mg}$ of Ae. geniculata, which harbors a homoeologous recombination promoter factor (Koo et al., 2016). Recombination frequencies between $H$. vulgare and $H$. bulbosum homoeologues have been previously detected but are lower than association frequencies (Zhang et al., 1999), probably because of non-chiasmate associations (Orellana, 1985). Homologous pairing has been also described in the absence of synapsis and meiotic recombination in Caenorhabditis elegans (Dernburg et al., 1998). Our results showed that homoeologous $H$. chilense and $H$. vulgare chromosomes associated in pairs in wheat in the absence of crossing over and that the Ph1 locus does not prevent such chromosome recognition and association between homoeologues. It is also worthy to mention that, although $H$. chilense and $H$. vulgare are phylogenetically quite distant, even included in two different sections among the Hordeum genus (Blattner, 2009), both species share a high degree 
TABLE 1 | (A) Total number of PMCs scored at anaphase I showing the different combinations observed for both Hordeum chromosomes added to the wheat background. The most frequent observation per line and the total number of meiocytes examined are shown in bold. (B) Quantification of meiocytes (\%) for each observation.

(A)

Number of PMCs scored in Anaphase I

\begin{tabular}{|c|c|c|c|c|c|c|}
\hline & & & & & & Total \\
\hline $7 \mathrm{H}^{\text {ch }} 7 \mathrm{H}^{v}$ addition & 23 & 49 & 9 & 35 & 12 & 128 \\
\hline $7 \mathrm{H}^{\mathrm{ch}} 5 \mathrm{H}^{\mathrm{v}}$ addition & 24 & 19 & 12 & 6 & 16 & 77 \\
\hline $5 \mathrm{H}^{c h} 5 \mathrm{H}^{v}$ addition & 35 & 22 & 5 & 14 & 10 & 86 \\
\hline Total & 82 & 90 & 26 & 55 & 38 & 291 \\
\hline
\end{tabular}

(B)
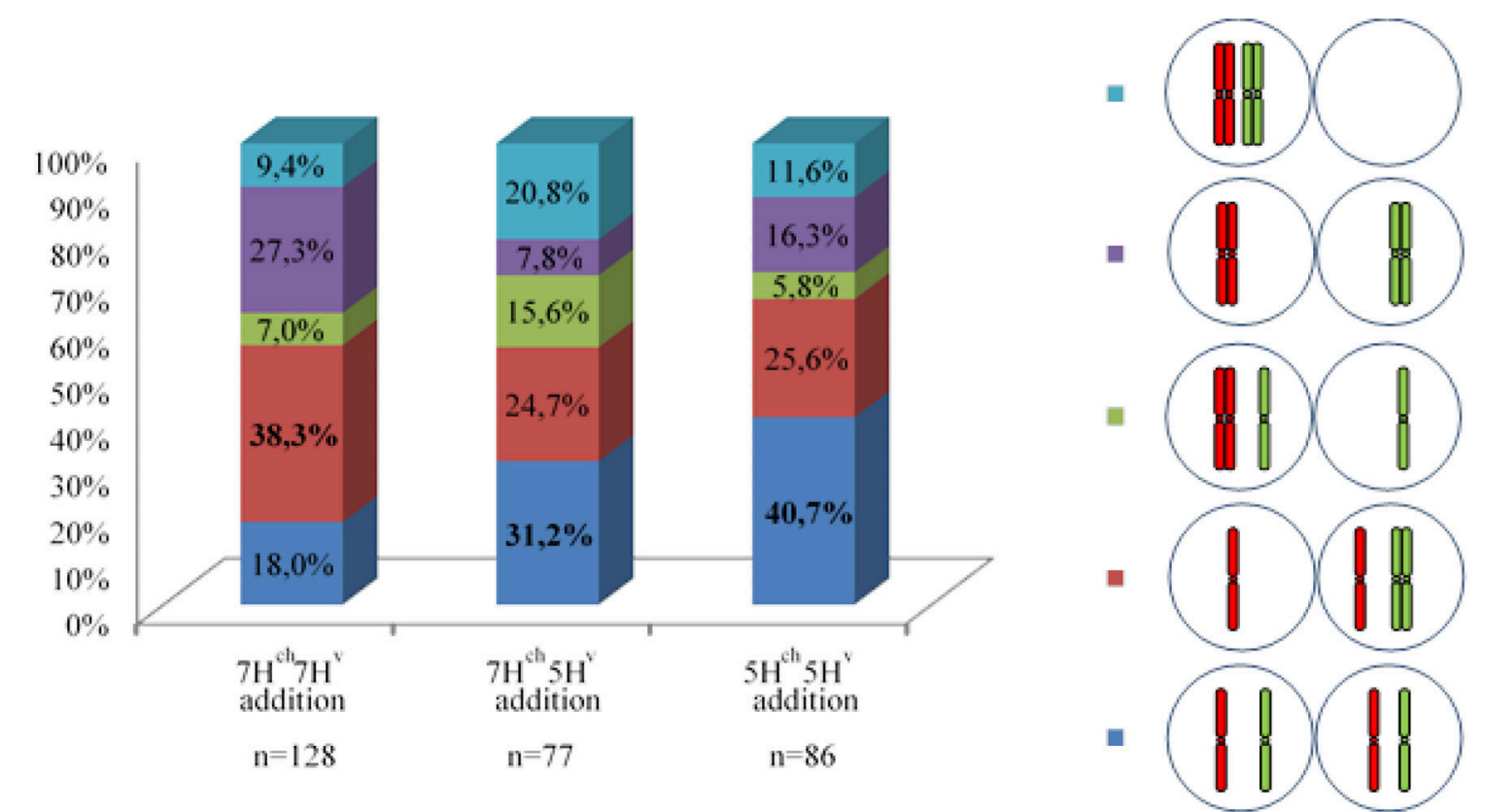

of similarities at the chromosomal level, as it has been reported between them and other species within this genus (Hernández et al., 2001; Aliyeva-Schnorr et al., 2016). Thus, other elements such as cohesins or the DNA sequence itself might play a major role on chromosome recognition and pairing at the onset of meiosis in a polyploidy like wheat.

So far, it is unclear whether initial recognition is mediated through protein-protein interactions, DNA base-pairing, or other chromosomal features. For example, a noncoding RNA (meiRNA-L) is responsible for the recombination-independent pairing of homologous loci in Schizosaccharomyces pombe (Ding et al., 2012). Other chromosomal features different from DNA/DNA recombinational interactions or RNA-mediated pairing have been proposed to be involved in the homologous recognition such as the pattern of cohesins distribution in the axial elements of unmatched meiotic chromosomes in mice and S. pombe (Ishiguro et al., 2011; Ding et al., 2016).
Subtelomeres have been also reported as crucial to promote chromosome recognition and pairing between homologous chromosomes (González-García et al., 2006; Calderón et al., 2014). In our study, variability for the HvT01 subtelomeric sequence was found between $H$. chilense and $H$. vulgare chromosomes 5 and 7, particularly for the long arm of both chromosomes. We observed that although homoeologous chromosomes can potentially associate by the telomeres, subtelomeric DNA blocks might hamper homoeologous chromosome to correctly associate in pairs and thus, in the absence of homologs, chromosome recognition and association between homoeologues can occurred by the chromosome end where the subtelomeric repeats are shorter or absent. However, as meiosis progressed, the pairing signal initiated at these chromosome ends can be propagated along the whole chromosome, so that the homoeologues became fully associated by late pachytene. Thus, our results might suggest 


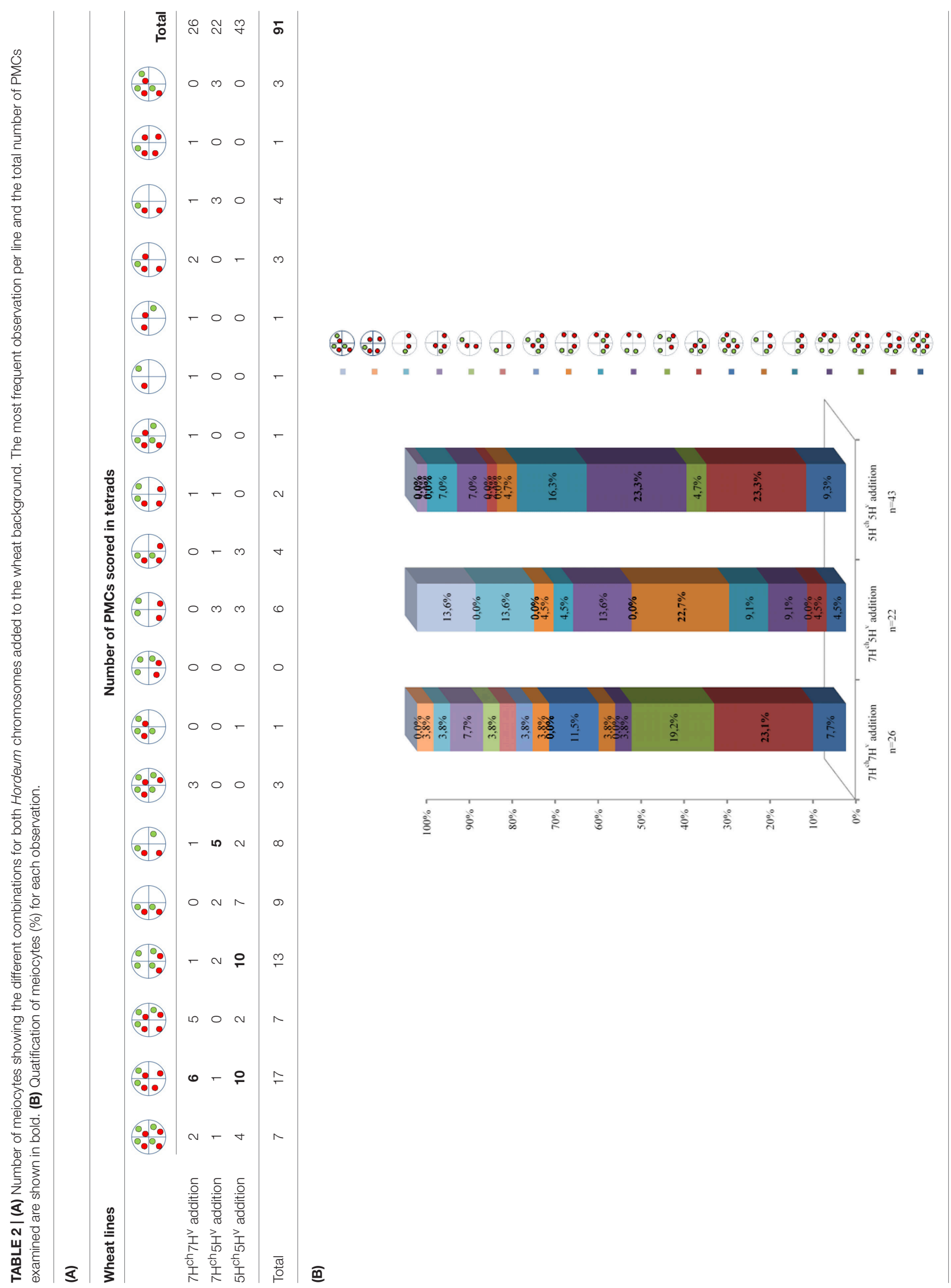



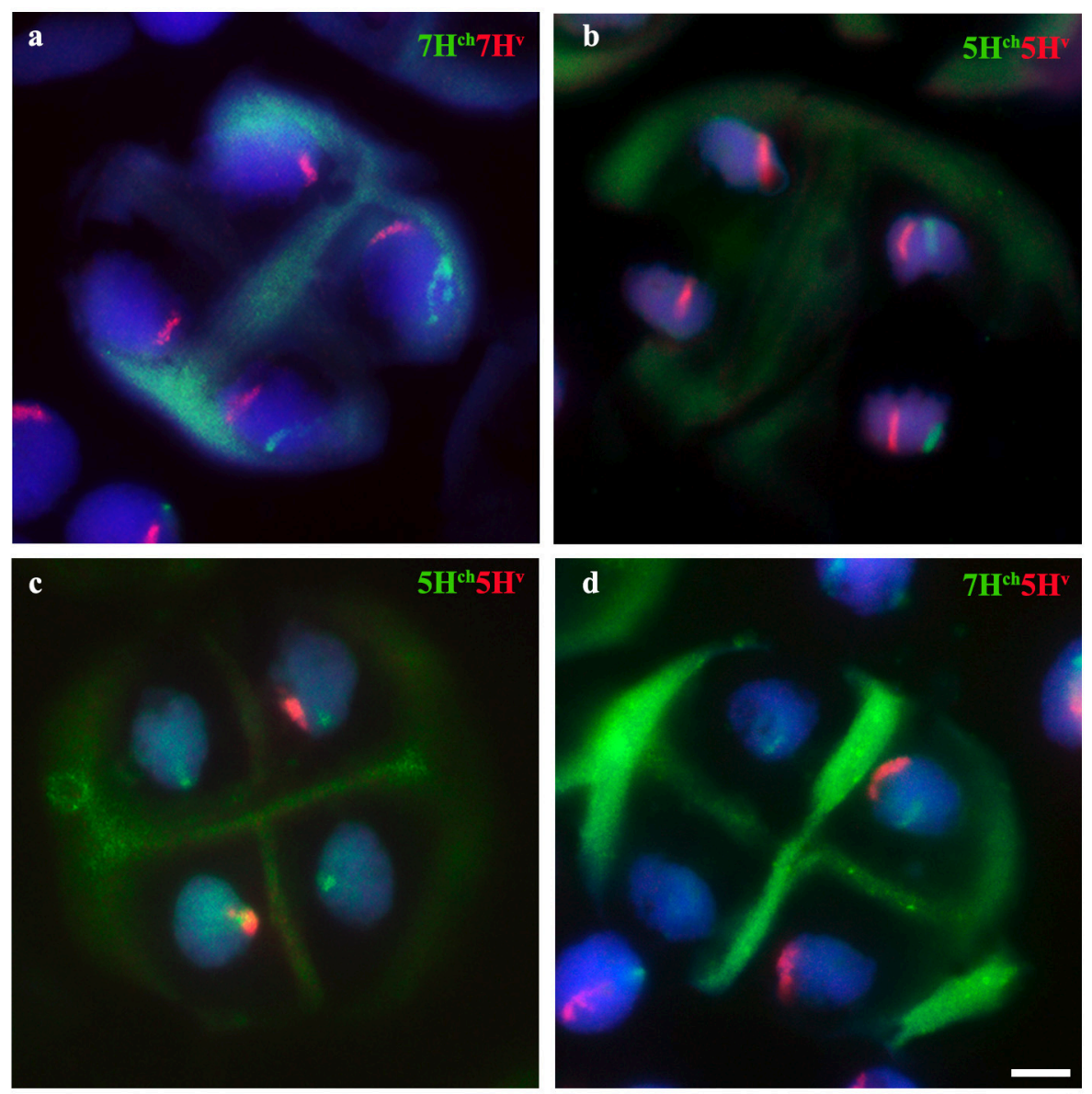

FIGURE 7 | Behavior of $H$. chilense and $H$. vulgare chromosomes in double monosomic Hordeum addition lines in wheat after the second meiosis division. Examples of the most frequent observations for both $\mathrm{H}$. chilense (green) and $\mathrm{H}$. vulgare (red) chromosomes are shown. DNA was counterstained with DAPI (blue). (a) Hordeum vulgare and $\mathrm{H}$. chilense chromatin detected in four and two PMCs, respectively, in the double monosomic $7 \mathrm{H}^{\mathrm{ch}} 7 \mathrm{H}^{\vee}$ wheat line. (b) $\mathrm{Hordeum}$ vulgare and $\mathrm{H}$. chilense chromatin detected in four and in two PMCs, respectively, in the double monosomic $5 \mathrm{H}^{\mathrm{ch}} 5 \mathrm{H}^{\vee}$ wheat line. (c) Four $H$. chilense signals and two $H$. vulgare signals were observed in the double monosomic $5 \mathrm{H}^{\mathrm{ch}} 5 \mathrm{H}^{\mathrm{v}}$ wheat line at the same frequency as reported in $\mathbf{b}$. (d) Wild and cultivated barley signals are present in the same nucleus and only one each in another two different nucleus. Bar represents $10 \mu \mathrm{m}$.

that subtelomeres can play a key role in the specificity of chromosome recognition, restricting chromosome recognition to true homologs and therefore hampering homoeologous chromosomes to recognize each other and associate. The implication was that DNA sequence(s) within the subtelomeric region must be important for the process of initial homolog recognition and pairing, although further studies are required to reveal how subtelomeres take part in such important meiosis processes.

The peculiarities of univalent behavior in meiosis have been extensively studied in wheat aneuploids, particularly for the relation between the means of a chromosome segregation and its inclusion into a microspore (Sears, 1952; Marais and Marais, 1994; Friebe et al., 2005; Lukaszewski, 2010). The knowledge about univalent behavior in meiosis is necessary for the directed development of wheat lines carrying alien introgressions since univalent are subjected of incorrect division and segregation. Thus, abnormities in meiosis result in various modifications and/or in the loss of a transferred chromosome (Silkova et al., 2014). Univalents in meiosis have a tendency to misdivide (break) across their centromeres producing telocentric. This process has been deeply described in wheat (Sears, 1952; Steinitz-Sears, 1966; Friebe et al., 2005), and used to generate different cytogenetic stocks (Sears and Sears, 1978; Lukaszewski, 1993, 1997). The most common alien introgression in wheat, chromosome translocations, is the result of centric misdivision and fusion of misdivision products. Translocations between $H$. chilense and $H$. vulgare have been detected previously when the genomes of these species are in the same background (Prieto et al., 2001). Our results overview the univalent behavior of two homoeologous and non-homoeologous barley chromosomes in the wheat background. We observed that chromosome misdivisions and sister chromatids segregated randomly at anaphase I similarly to previous works (Friebe et al., 2005), and independently of whether or not related chromosomes associate in pairs in early meiosis. 
In summary, homoeologous wild and cultivated barley chromosomes were observed fully associated in pairs in early meiosis in the presence of the $P h 1$ although crossing over did not occur at any time, as both chromosomes were always visualized as univalents during metaphase I. Whether or not homoeologous Hordeum chromosomes can crossover in the absence of the Phl locus remains to be elucidated. In addition, the role of the terminal chromosome regions in chromosome recognition and paring and the proteins interacting with these chromosomes ends will be key questions to shed light in future works.

\section{HUMAN AND ANIMAL RIGHTS AND INFORMED CONSENT}

This article does not contain any studies with human participants or animals.

\section{REFERENCES}

Aliyeva-Schnorr, L., Stein, N., and Houben, A. (2016). Collinearity of homoeologous group 3 chromosomes in the genus Hordeum and Secale cereale as revealed by $3 \mathrm{H}$-derived FISH analysis. Chromosome Res. 24, 231-242. doi: 10.1007/s10577-016-9518-8

Aragón-Alcaide, L., Miller, T., Schwarzacher, T., Reader, S., and Moore, G. (1996). A cereal centromeric sequence. Chromosoma 105, 261-268. doi: $10.1007 /$ BF02524643

Aragón-Alcaide, L., Reader, S., Beven, A., Shaw, P., Miller, T., and Moore, G. (1997). Association of homologous chromosomes during floral development. Curr. Biol. 7, 905-908.

Belostotsky, D. A., and Ananiev, E. V. (1990). Characterization of relic DNA from barley genome. Theor. Appl. Genet. 80, 374-380. doi: 10.1007/BF00210075

Blattner, F. R. (2009). Progress in phylogenetic analysis and a new infrageneric classification of the barley genus Hordeum (Poaceae: Triticeae). Breed. Sci. 59, 471-480. doi: 10.1270/jsbbs.59.471

Calderón, M. C., Ramírez, M. C., Martín, A., and Prieto, P. (2012). Development of Hordeum chilense introgression lines in durum wheat: a tool for breeders and complex trait analysis. Plant Breed. 131, 733-738. doi: 10.1111/j.1439-0523.2012.02010.x

Calderón, M. C., Rey, M.-D., Cabrera, A., and Prieto, P. (2014). The subtelomeric region is important for chromosome recognition and pairing during meiosis. Sci. Rep. 4:6488. doi: 10.1038/srep06488

Colas, I., Shaw, P., Prieto, P., Wanous, M., Spielmeyer, W., Mago, R., et al. (2008). Effective chromosome pairing requires chromatin remodeling at the onset of meiosis. Proc. Natl. Acad. Sci. U.S.A. 105, 6075-6080. doi: 10.1073/pnas.0801521105

Corredor, E., Lukaszewski, A. J., Pachon, P., Allen, D. C., and Naranjo, T. (2007). Terminal regions of wheat chromosomes select their pairing partners in meiosis. Genetics 177, 699-706. doi: 10.1534/genetics.107.078121

Corredor, E., and Naranjo, T. (2007). Effect of colchicine and telocentric chromosome conformation on centromere and telomere dynamics at meiotic prophase I in wheat-rye additions. Chromosome Res. 15, 231-245. doi: 10.1007/s10577-006-1117-7

Dernburg, A. F., McDonald, K., Moulder, G., Barstead, R., Dresser, M., and Villeneuve, A. M. (1998). Meiotic recombination in C. elegans initiates by a conserved mechanism and is dispensable for homologous chromosome synapsis. Cell 94, 387-398. doi: 10.1016/S0092-8674(00)81481-6

Ding, D. Q., Matsuda, A., Okamasa, K., Nagahama, Y., Haraguchi, T., and Hiraoka, Y. (2016). Meiotic cohesin-based chromosome structure is essential for homologous chromosome pairing in Schizosaccharomyces pombe. Chromosoma 125, 205-214. doi: 10.1007/s00412-015-0551-8

\section{AUTHORS CONTRIBUTIONS}

All authors contributed to this manuscript. MC and PP designed the research and performed the experiments. MC, $\mathrm{MR}$, AM, and PP analyzed, discussed the results. PP and $\mathrm{MC}$ wrote the manuscript. All authors read and approved the manuscript.

\section{ACKNOWLEDGMENTS}

This research was supported by grants AGL2015-64833R from Spanish Ministerio de Economía y Competitividad (MINECO) and ERC-StG- 243118 from the FP7 and The European Regional Development Fund (FEDER) from the European Union. Authors deeply appreciate the comments from the independent reviewers during the revision of the manuscript.

Ding, D. Q., Okamasa, K., Yamane, M., Tsutsumi, C., Haraguchi, T., Yamamoto, M., et al. (2012). Meiosis-specific noncoding RNA mediates robust pairing of homologous chromosomes in meiosis. Science 336, 732-736. doi: $10.1126 /$ science. 1219518

Eichler, E. E., and Sankoff, D. (2003). Structural dynamics of eukaryotic chromosome evolution. Science 301, 793-797. doi: 10.1126/science.1086132

Friebe, B., Zhang, P., Linc, G., and Gill, B. S. (2005). Robertsonian translocations in wheat arise by centric misdivision of univalents at anaphase I and rejoining of broken centromeres during interkinesis of meiosis II. Cytogenet. Genome Res. 109, 293-297. doi: 10.1159/000082412

Ganal, M. W., Lapitan, N. L., and Tanksley, S. D. (1991). Macrostructure of the tomato telomeres. Plant Cell 3, 87-94. doi: 10.1105/tpc.3.1.87

Godfray, H. C., Crute, I. R., Haddad, L., Lawrence, D., Muir, J. F., Nisbett, N., et al. (2010). The future of the global food system. Phil. Trans. R. Soc. B. 365, 2769-2777. doi: 10.1098/rstb.2010.0180

González-García, M., González-Sánchez, M., and Puertas, M. J. (2006). The high variability of subtelomeric heterochromatin and connections between nonhomologous chromosomes, suggest frequent ectopic recombination in rye meiocytes. Cytogenet. Genome Res. 115, 179-185. doi: 10.1159/000095240

Greer, E., Martin, A. C., Pendle, A., Colas, I., Jones, A. M. E., Moore, G., et al. (2012). The Ph1 locus suppresses Cdk2-type activity during premeiosis and meiosis in wheat. Plant Cell 24, 152-162. doi: 10.1105/tpc.111.094771

Hagras, A. A. A., Masahiro, K., Tanaka, K., Sato, K., and Tsujimoto, H. (2005). Genomic differentiation of Hordeum chilense from $H$. vulgare as revealed by repetitive and EST sequences. Genes Genet. Syst. 80, 147-159. doi: $10.1266 /$ ggs.80.147

Heacock, M., Spangler, E., Riha, K., Puizina, J., and Shippen, D. E. (2004). Molecular analysis of telomere fusions in Arabidopsis: multiple pathways for chromosome end-joining. EMBO J. 23, 2304-2313. doi: 10.1038/sj.emboj.7600236

Hernández, P., Dorado, G., Prieto, P., Giménez, M. J., Ramírez, M. C., Laurie, D. A., et al. (2001). A core genetic map of Hordeum chilense and comparisons with maps of barley (Hordeum vulgare) and wheat (Triticum aestivum). Theor. Appl. Genet. 102, 1259-1264. doi: 10.1007/s001220000514

Hudakova, S., Michalek, W., Presting, G. G., ten Hoopen, R., dos Santos, K., Jasencakova, Z., et al. (2001). Sequence organization of barley centromeres. Nucleid Acids Res. 29, 5029-5035. doi: 10.1093/nar/29.24.5029

Ishiguro, K., Kim, J., Fujiyama-Nakamura, S., Kato, S., and Watanabe, Y. (2011). A new meiosis-specific cohesin complex implicated in the cohesin code for homologous pairing. EMBO Rep. 12, 267-275. doi: 10.1038/embor.2011.2

Islam, A. K. M. R., Shepherd, K. W., and Sparrow, D. H. B. (1978). "Production and characterization of wheat-barley addition lines," in Proceedings 5th International Wheat Genetics Symposium (New Delhi), 365-371. 
Islam, A. K. M. R., Shepherd, K. W., and Sparrow, D. H. B. (1981). Isolation and characterization of euplasmic wheat-barley chromosome addition lines. Heredity 46, 161-174. doi: 10.1038/hdy.1981.24

Koo, D. H., Liu, W. X., Friebe, B., and Gill, B. S. (2016). Homoeologous recombination in the presence of $\mathrm{Ph} 1$ gene in wheat. Chromosoma 126, 531-540. doi: 10.1007/s00412-016-0622-5

Koszul, R., Kim, K. P., Prentiss, M., Kleckner, N., and Kameoka, S. (2008). Meiotic chromosomes move by linkage to dynamic actin cables with transduction of force through the nuclear envelope. Cell 133, 1188-1201. doi: 10.1016/j.cell.2008.04.050

Kotani, H., Hosouchi, T., and Tsuruoka, H. (1999). Structural Analysis and Complete Physical Map of Arabidopsis thaliana Chromosome 5 Including Centromeric and Telomeric Regions. DNA Res. 6, 381-386. doi: 10.1093/dnares/6.6.381

Liu, S. B., Wang, H. G., Zhang, X. Y., Li, X. F., Li, D. Y., Duan, X. Y., et al. (2005). Molecular cytogenetic identification of a wheatThinopyron intermedium (Host) Barkworth \& DR Dewey partial amphiploid resistant to powdery mildew. J. Integr. Plant. Biol. 47, 726-733. doi: 10.1111/j.1744-7909.2005.00051.x

Liu, Z. W., Biyashev, R. M., and Saghai Maroof, M. A. (1996). Development of simple sequence repeat DNA markers and their integration into a barley linkage map. Theor. Appl. Genet. 93, 869-876. doi: 10.1007/BF00224088

Lukaszewski, A. J. (1993). Reconstruction in wheat of complete chromosome-1B and chromosome-1R from the 1RS.1BL translocation of Kavkaz origin. Genome 36, 821-824. doi: 10.1139/g93-109

Lukaszewski, A. J. (1997). Further manipulation by centric misdivision of the 1RS.1BL translocation in wheat. Euphytica 94, 257-261. doi: 10.1023/A:1002916323085

Lukaszewski, A. J. (2000). Manipulation of the 1RS.1BL translocation in wheat by induced homoeologous recombination. Crop Sci. 40, 216-225. doi: $10.2135 /$ cropsci2000.401216x

Lukaszewski, A. J. (2010). Behavior of centromeres in univalents and centric misdivision in wheat. Cytogenet. Genome Res. 129, 97-109. doi: $10.1159 / 000314108$

Maestra, B., de Jong, J. H., Shepherd, K., and Naranjo, T. (2002). Chromosome arrangement and behaviour of two rye homologous telosomes at the onset of meiosis in disomic wheat-5RL addition lines with and without the Ph1 locus. Chromosome Res. 10, 655-667. doi: 10.1023/A:1021564327226

Marais, G. F., and Marais, A. S. (1994). The derivation of compensating translocations involving homoeologous group- 3 chromosomes of wheat and rye. Euphytica 79, 75-80. doi: 10.1007/BF00023578

Martín, A. C., Rey, M. D., Shaw, P., and Moore, G. (2017). Dual effect of the wheat Ph1 locus on chromosome synapsis and crossover. Chromosoma 126, 669-680. doi: $10.1007 / \mathrm{s} 00412-017-0630-0$

Martín, A. C., Shaw, P., Phillips, D., Reader, S., and Moore, G. (2014). Licensing MLH1 sites for crossover during meiosis. Nat. Commun. 5:4580. doi: $10.1038 /$ ncomms 5580

Martín, A., and Sanchez-Monge Laguna, E. (1982). Cytology and morphology of the amphiploid Hordeum chilense x Triticum turgidum conv. durum. Euphytica 31, 261-267. doi: 10.1007/BF00028329

Martinez-Perez, E., Shaw, P., Aragon-Alcaide, L., and Moore, G. (2003). Chromosomes form into seven groups in hexaploid and tetraploid wheat as a prelude to meiosis. Plant J. 36, 21-29. doi: 10.1046/j.1365-313X.2003. 01853.x

Martinez-Perez, E., Shaw, P., and Moore, G. (2000). Polyploidy induces centromere association. J. Cell Biol. 148, 233-238. doi: 10.1083/jcb.148.2.233

Martinez-Perez, E., Shaw, P., and Moore, G. (2001). The Ph1 locus is needed to ensure specific somatic and meiotic centromere association. Nature 411, 204-207. doi: 10.1038/35075597

Mikhailova, E. I., Naranjo, T., Shepherd, K., Eden, J. W., Heyting, C., and de Jong, J. H. (1998). The effect of the wheat Ph1 locus on chromatin organization and meiotic chromosome pairing analysed by genome painting. Chromosoma 107, 339-350. doi: 10.1007/s004120050316

Miller, T. E., Reader, S. M., and Chapman, V. (1982). "The addition of Hordeum chilense chromosomes to wheat," in Paper Presented at the Proceedings of the International Symposium Eucarpia on Induced Variability in Plant Breeding. (Pudoc, Wageningen), 79-81.
Molnár-Láng, M., Linc, G., Logojan, A., and Sutka, J. (2000). Production and meiotic pairing behaviour of new hybrids of winter wheat (Triticum aestivum) $\mathrm{x}$ winter barley(Hordeum vulgare). Genome 43, 1045-1054. doi: 10.1139/g00-079

Molnár-Láng, M., Linc, G., and Szakács, E. (2014). Wheat-barley hybridization: the last 40 years. Euphytica 195, 315-329. doi: 10.1007/s10681-013-1009-9

Moore, G. (2002). Meiosis in allopolyploids - the importance of 'Teflon' chromosomes. Trends Genet. 18, 456-463. doi: 10.1016/S0168-9525(02)02730-0

Moore, G. (2014). "The control of recombination in wheat by $\mathrm{Ph} 1$ and its use in breeding," in Methods in Molecular Biology, ed N. J. Clifton (New York, NY: Humana Press), 143-153.

Moore, G., and Shaw, P. J. (2009). Improving the chances of finding the right partner. Curr. Opin. Genet. Dev. 19, 99-104. doi: 10.1016/j.gde.2009.02.006

Naranjo, T., and Corredor, E. (2008). Nuclear architecture and chromosome dynamics in the search of the pairing partner in meiosis in plants. Cytogenet. Genome Res. 120, 320-330. doi: 10.1159/000121081

Naranjo, T., Maestra, B., and Corredor, E. (2005). The search of the homologous partner at early meiosis in wheat. Chromosome Res. 13:9.

Naranjo, T., Valenzuela, N. T., and Perera, E. (2010). Chiasma frequency is region specific and chromosome conformation dependent in a rye chromosome added to wheat. Cytogenet. Genome Res. 129, 133-142. doi: 10.1159/000314029

Omara, J. G. (1953). The cytogenetics of Triticale. Bot. Rev. 19, 587-605. doi: $10.1007 / \mathrm{BF} 02861827$

Orellana, J. (1985). Most of the homoeologous pairing at metaphase-i in wheat-rye hybrids is not chiasmatic. Genetics 111, 917-931.

Prieto, P., Martin, A., and Cabrera, A. (2004b). Chromosomal distribution of telomeric and telomeric-associated sequences in Hordeum chilense by in situ hybridization. Hereditas 141, 122-127. doi: 10.1111/j.1601-5223.2004.01825.x

Prieto, P., Moore, G., and Reader, S. (2005). Control of conformation changes associated with homologue recognition during meiosis. Theor. Appl. Genet. 111, 505-510. doi: 10.1007/s00122-005-2040-6

Prieto, P., Ramirez, M. C., Ballesteros, J., and Cabrera, A. (2001). Identification of intergenomic translocations involving Wheat, Hordeum vulgare and Hordeum chilense chromosomes by FISH. Hereditas 135, 171-174. doi: 10.1111/j.1601-5223.2001.t01-1-00171.x

Prieto, P., Shaw, P., and Moore, G. (2004a). Homologue recognition during meiosis is associated with a change in chromatin conformation. Nature Cell Biol. 6, 906-908. doi: 10.1038/ncb1168

Rey, M. D., Calderón, M. C., and Prieto, P. (2015b). The use of the ph1b mutant to induce recombination between the chromosomes of wheat and barley. Front. Plant Sci. 6:160. doi: 10.3389/fpls.2015.00160

Rey, M. D., Calderón, M. C., Rodrigo, M. J., Zacarías, L., Alós, E., and Prieto, P. (2015a). Novel bread wheat lines enriched in carotenoids carrying Hordeum chilense chromosome arms in the ph1b background. PLOS ONE 10:e134598. doi: 10.1371/journal.pone.0134598

Rey, M. D., Martin, A. C., Higgins, J., Swarbreck, D., Uauy, C., Shaw, P., et al. (2017). Exploiting the ZIP4 homologue within the wheat Ph1 locus has identified two lines exhibiting homoeologous crossover in wheat-wild relative hybrids. Mol. Breed. 37:95. doi: 10.1007/s11032-017-0700-2

Richards, D. M., Greer, E., Martin, A. C., Moore, G., Shaw, P. J., et al. (2012). Quantitative dynamics of telomere bouquet formation. PLoS Comput. Biol. 8:e1002812. doi: 10.1371/journal.pcbi.1002812

Riley, R., and Chapman, V. (1958).Genetic control of the cytologically diploid behaviour of hexaploid wheat. Nature 182, 713-715. doi: 10.1038/18 2713a0

Schubert, I., Shi, F., Fuchs, J., and Endo, T. R. (1998). An efficient screening for terminal deletions and translocations of barley chromosomes added to common wheat. Plant J. 14, 489-495. doi: 10.1046/j.1365-313X.1998.00125.x

Schwarzacher, T., and Heslop-Harrison, J. S. (1991). In situ hybridization to plant telomeres using synthetic oligomers. Genome 34, 317-323. doi: $10.1139 / \mathrm{g} 91-052$

Sears, E. R. (1952). Misdivision of univalents in common wheat. Chromosoma 4, 535-550.

Sears, E. R. (1976). Genetic control of chromosome pairing in wheat. Ann. Rev. Genet. 10, 31-51. doi: 10.1146/annurev.ge.10.120176.000335

Sears, E. R., and Sears, L. M. S. (1978). "The telocentric chromosomes of common wheat," Proceedings of 5th International Wheat Genetics Symposium (New Delhi), 389-407. 
Silkova, O. G., Kabanenko, Y. N., and Loginova, D. V. (2014). The effect of wheat-rye substitution on chromosome elimination: an analysis of univalents' behavior in wheat meiosis with dimonosomy and tetramonosomy. Russ. J. Genet. 50, 245-252. doi: 10.1134/S102279541402015X

Simpson, P. R., Newman, M. A., Davies, D. R., Noel Ellis, T. H., Matthews, P. M., and Lee, D. (1990). Identification of translocations in pea by in situ hybridization with chromosome-specific probes. Genome 33, 745-749. doi: $10.1139 / \mathrm{g} 90-112$

Steinitz-Sears, L. M. (1966). Somatic instability of telocentric chromosomes in wheat and the nature of the centromere. Genetics 54, 241-248.

Valenzuela, N. T., Perera, E., and Naranjo, T. (2012). Identifying crossover-rich regions and their effect on meiotic homologous interactions by partitioning chromosome arms of wheat and rye. Chromosome Res. 21, 433-445. doi: 10.1007/s10577-013-9372-x

Valenzuela, N. T., Perera, E., and Naranjo, T. (2013). Dynamics of rye chromosome $1 \mathrm{R}$ regions with high and low crossover frequency in homology search and synapsis development. PLoS ONE 7:e36385. doi: 10.1371/journal.pone.0036385
Zhang, L. T., Pickering, R., and Murray, B. (1999). Direct measurement of recombination frequency in interspecific hybrids between Hordeum vulgare and $H$. bulbosum using genomic in situ hybridization. Heredity 83, 304-309. doi: 10.1038/sj.hdy. 6885710

Conflict of Interest Statement: The authors declare that the research was conducted in the absence of any commercial or financial relationships that could be construed as a potential conflict of interest.

Copyright () 2018 Calderón, Rey, Martín and Prieto. This is an open-access article distributed under the terms of the Creative Commons Attribution License (CC BY). The use, distribution or reproduction in other forums is permitted, provided the original author(s) and the copyright owner are credited and that the original publication in this journal is cited, in accordance with accepted academic practice. No use, distribution or reproduction is permitted which does not comply with these terms. 